\title{
WIDE SLIT RECTANGULAR MICROSTRIP ANTENNA WITH SPIRAL EBG STRUCTURE
}

\author{
Savita M Shaka. ${ }^{1}$ Vani R.M. ${ }^{2}$ Prashant R.T ${ }^{3}$, Hunagund P.V ${ }^{4}$

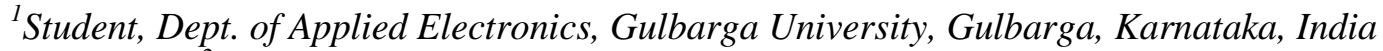 \\ ${ }^{2}$ Head, USIC, Gulbarga University, Gulbarga, Karnataka, India \\ ${ }^{3}$ Student, Dept. of Applied Electronics, Gulbarga University, Gulbarga, Karnataka, India \\ ${ }^{4}$ Professor, Dept. of Applied Electronics, Gulbarga University, Gulbarga, Karnataka, India
}

\begin{abstract}
This paper introduces high impedance Electromagnetic Bang Gap $(E B G)$ structure and investigates the performance of rectangular microstrip antenna embedded on a high impedance spiral EBG structure on ground plane. By loading EBG there is increase in bandwidth of the proposed antenna when compared with conventional RMSA. There is a suppression of surface waves which improves antennas radiation pattern and Back lobe level reduces.
\end{abstract}

Keywords: Rectangular Microstrip antenna, wide slit, Electromagnetic Band Gap (EBG) structure, bandwidth.

\section{INTRODUCTION}

Microstrip patch antennas have been studied extensively over the past many years because of its low profile structure, light weight, and low cost in fabrication planar and non planar surfaces, compatibility designs, and mechanically robust flexibility when mounted on rigid surfaces[1].They are extremely compatible for embedded antennas in handheld wireless devices such as cellular phones, pagers, etc. These low profile antennas are also useful in aircraft, satellite and missile applications where size, weight, cost, performance, ease of installation, and aerodynamic profile are strict constraints [2]. Some of the principal advantages of this type of antennas are low profile etc. However, a major drawback of these antennas is the narrow bandwidth [3].

There have been various efforts from researchers towards increasing its bandwidth. Recently, Electromagnetic Band Gap (EBG) structures have attracted much attention among researchers in the microwave and antennas communities due to their excellent pass and rejection frequency band characteristics [4-5]. In general, EBG structure is a periodic structure that forbids the propagation of all electromagnetic surface waves within a particular frequency band called the band gap. It permits additional control of the behavior of electromagnetic waves other than conventional guiding and/or filtering structures [6-7]. EBG has the potential to provide a simple and effective solution to the problems of surface and leaky waves.

In view of this, an effort is made to enhance the bandwidth of the rectangular microstrip antenna by using loading spiral EBG structure on the ground plane.

\section{DESCRIPTION OF ANTENNA GEOMETRY}

Fig. 1(a) shows the geometry of the proposed conventional RMSA. The antenna is designed by using low cost glass epoxy FR4 dielectric material with a relative permittivity $\varepsilon r=4.4$ with thickness $\mathrm{h}=1.6 \mathrm{~mm}$ is chosen. The conventional RMSA is designed for $6 \mathrm{GHz}$ with dimensions $\mathrm{L}$ and $\mathrm{W}$ radiating part, which is excited by simple $50 \Omega$ microstrip feed having dimensions length $\mathrm{Lf}$ and width Wf using quarter wave length transformer of dimension length $\mathrm{Lt}$ and $\mathrm{Wt}$ for their impedance matching. The length $\mathrm{Lg}$ and $\mathrm{Wg}$ of the ground plane of the antenna is calculated by $\mathrm{Lg}=6 \mathrm{~h}+\mathrm{L}$ and $\mathrm{Wg}=6 \mathrm{~h}+\mathrm{W}$ and all the dimensions are shown in table 1.

The study is carried by keeping all the parameter of the RMSA radiating patch constant. The antenna is fed by stripline fed and the ground plane of the antenna is kept constant. For obtaining dual wide slits RMSA (DWS-RMSA), a pair of wide slits is incorporated in one of the radiating edge of the rectangular Microstrip antenna. The two wide slits are placed at equal distance from the centerline of the patch width. ls= $9 \mathrm{~mm}$ and $\mathrm{ws}=1 \mathrm{~mm}$ are the slits length and slits width respectively $\mathrm{w}_{1}$ is the separation between these two slits. The geometry of the DWS-RMSA is as shown in the Fig.2 (a). The photographic view of the top and bottom of antenna is as shown in Fig.2 (b).

Initially the ground plane of the RMSA is replaced by a high impedance spiral EBG structure. By keeping all the parameter of the radiating patch constant, the antenna is fed by stripline fed. The geometry of the proposed antenna RMSAEBG is as shown in the Fig. 3(a). The ground plane is loaded with four arms metalstrip below the radiating patch of the antenna 
connected to the spiral EBG structure with metalstrip width $\mathrm{w}=1 \mathrm{~mm}$ and the gap between each metalstrip $\mathrm{g}=1 \mathrm{~mm}$ is used to improve the impedance matching and reduce the antenna size. The photographic view of the top and bottom of the RMSAEBG antenna is as shown in the Fig. 3(b).All the dimension of the spiral EBG is as shown in table2.

Further the study is carried out by replacing the ground plane of the DWS-RMSA by a high impedance spiral EBG structure. The parameter of radiating patch DWS-RMSA is kept constant. The geometry of the DWS-RMSAEBG is as shown in the Fig. 4(a). The ground plane is loaded with four arms metalstrip connected to the spiral EBG structure below the radiating patch of the antenna with metalstrip width $\mathrm{w}=$ $1 \mathrm{~mm}$ and the gap between each metalstrip $\mathrm{g}=1 \mathrm{~mm}$ is used to improve the impedance matching and reduce the antenna size. The photographic view of the DWS-RMSAEBG is as shown in the Fig. 4(b).

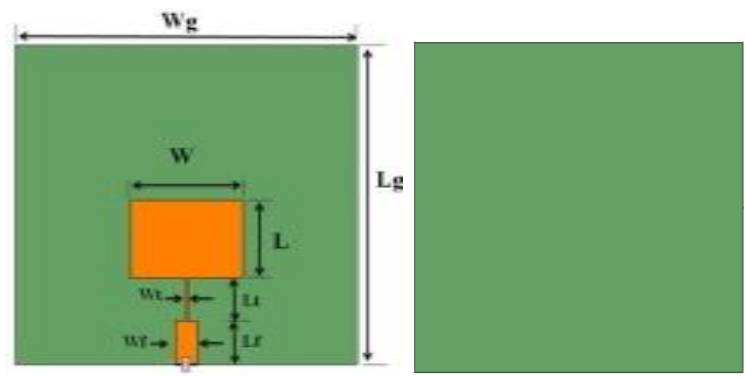

Fig-1 (a): Geometry of RMSA

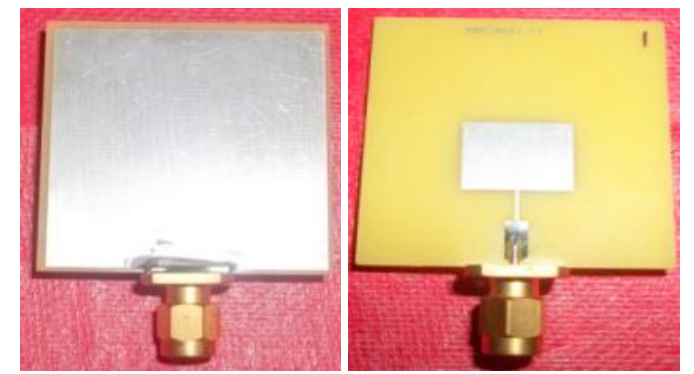

Fig-1 (b): Photographic view of top and bottom RMSA

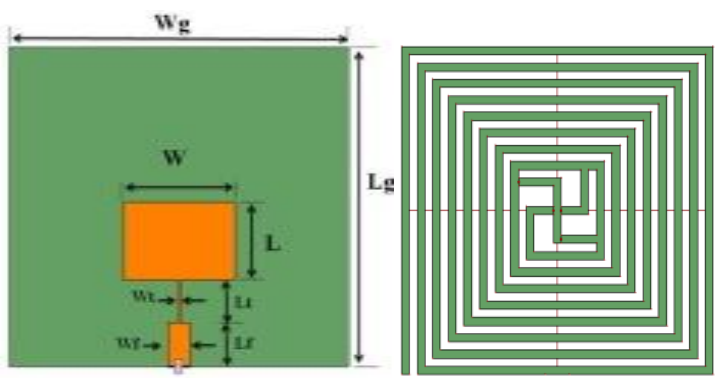

Fig-2 (a): Geometry of RMSA-EBG

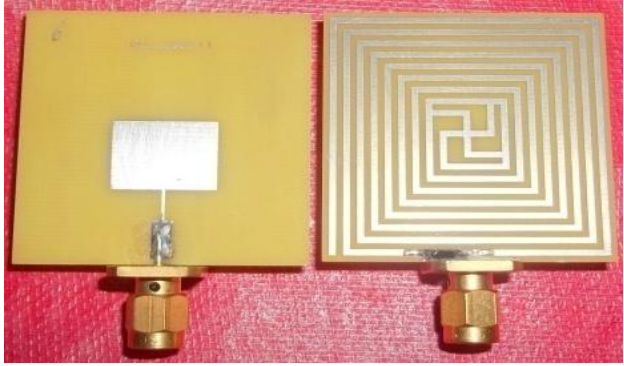

Fig.2 (b) Photographic view of top and bottom RMSA-EBG
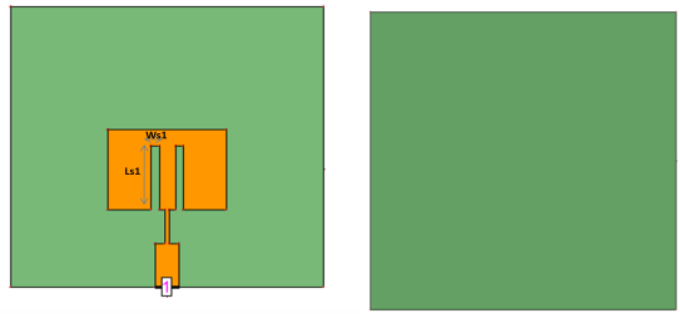

Fig-3 (a): Geometry of DW-RMSA

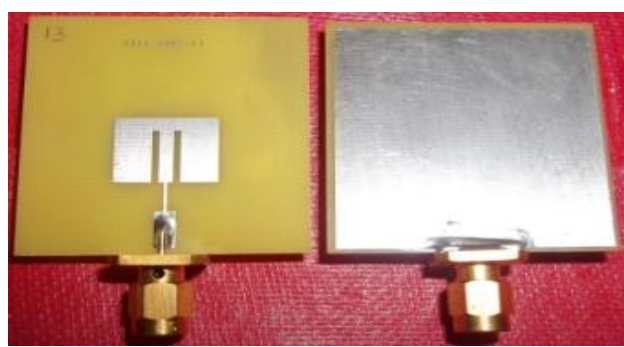

Fig-3 (b): Photographic view of top and bottom DW-RMSA
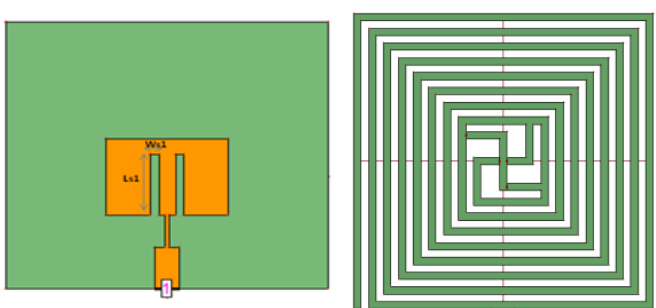

Fig-4(a): Geometry of DWRMSA-EBG

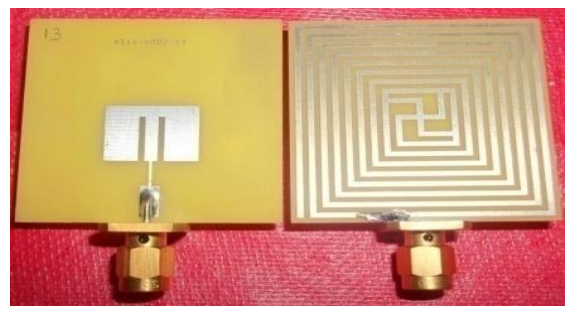

Fig-4(b): Photographic view of top and bottom DWRMSAEBG 
Table-1: Antenna parameters patch, ground plane

\begin{tabular}{|c|c|}
\hline Parameters & Size $(\mathbf{m m})$ \\
\hline Length of the patch(L) & 11.33 \\
\hline Width of the patch(W) & 15.24 \\
\hline $\begin{array}{l}\text { Length of the quarter wave } \\
\text { transformer(Lt) }\end{array}$ & 4.92 \\
\hline $\begin{array}{l}\text { Width of the quarter wave } \\
\text { transformer(Wt) }\end{array}$ & 0.50 \\
\hline Length of the $50 \Omega$ line(Lf50) & 6.18 \\
\hline Width of the $50 \Omega$ line(Wf50) & 3.06 \\
\hline Length of the ground plane $(\mathrm{Lg})$ & 40 \\
\hline Width of the ground plane $(\mathrm{Wg})$ & 40 \\
\hline
\end{tabular}

\section{EXPERIMENTAL RESULTS}

The bandwidth over return loss less than $-10 \mathrm{~dB}$ for the proposed antennas is measured. The measurements are taken on Vector Network Analyzer (Rohde and Schwarz, Germany make ZVK model 1127.8651). The variation of return loss versus frequency of RMSA is as shown in Fig 5. From this figure it is seen that, the antenna resonates very close to its designed frequency of $5.99 \mathrm{GHz}$. The overall bandwidth of the RMSA is $4.18 \%$. The bandwidth is calculated by using the equation,

$$
B W=\left[\frac{f 2-f 1}{f c}\right] \times 100 \%
$$

Where, $f 1$ and $f 2$ are the lower and upper cut-off frequencies of the band respectively, when its return loss reaches $-10 \mathrm{~dB}$ and $f_{\mathrm{C}}$ is the centre frequency between $f 1$ and $f 2$.

Fig.6 shows a variation of return loss versus frequency RMSA-EBG which gives six bands. The overall bandwidth of RMSA-EBG is $86.99 \%$ this is due to the loading of the EBG structure on the ground plane of the RMSA. The variation of return loss versus frequency of DW-RMSA antenna is as shown in Fig.7 it gives a three bands. The overall bandwidth of DWRMSA antenna is $26.30 \%$ this is due to the dual slit in the radiating patch of the RMSA. DWRMSA-EBG gives five bands. The return loss versus frequency of DWRMSA-EBG is as shown in the Fig.8 the overall bandwidth of the antenna is $114.36 \%$.The results are as shown in the table2.

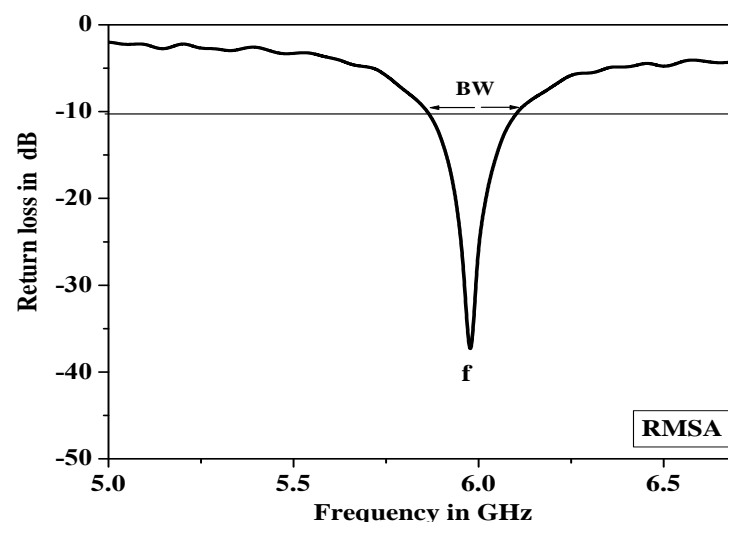

Fig-5: The return loss characteristics versus frequency of RMSA

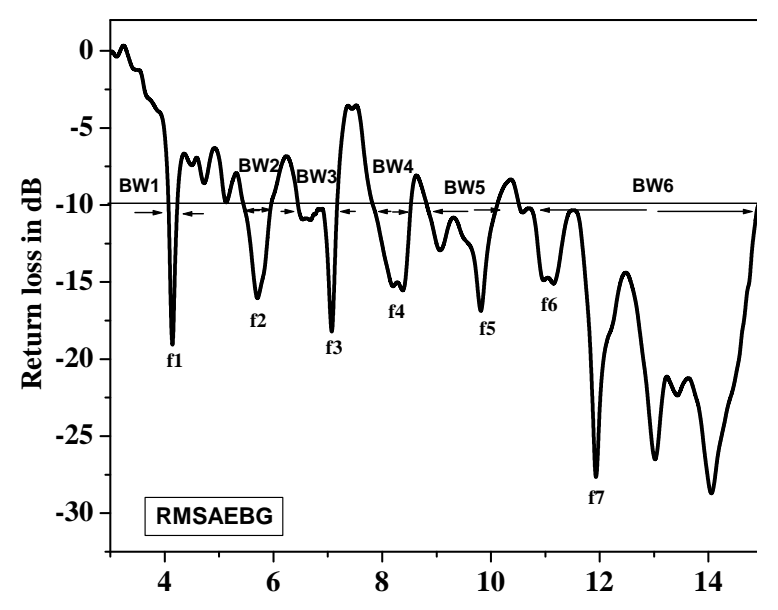

Fig-6: The return loss characteristics versus frequency of RMSA-EBG

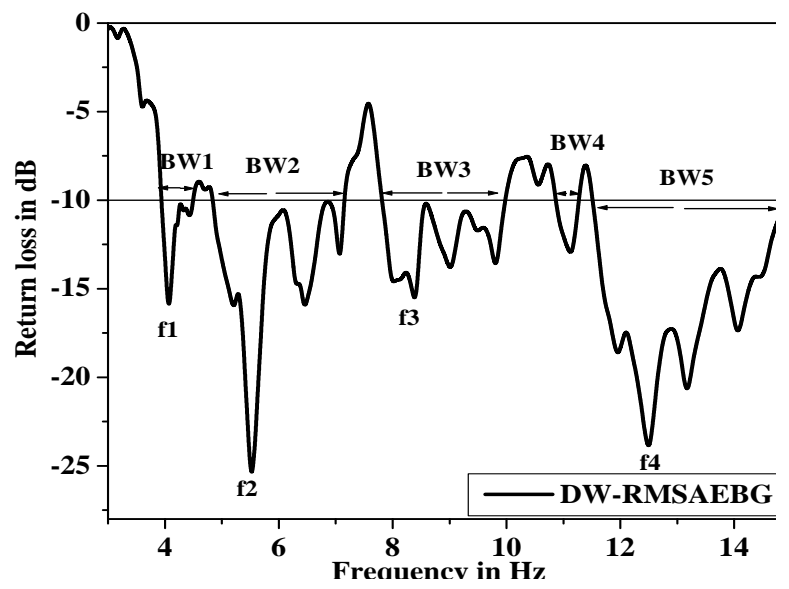

Fig-7: The return loss characteristics versus frequency of DWRMSA 


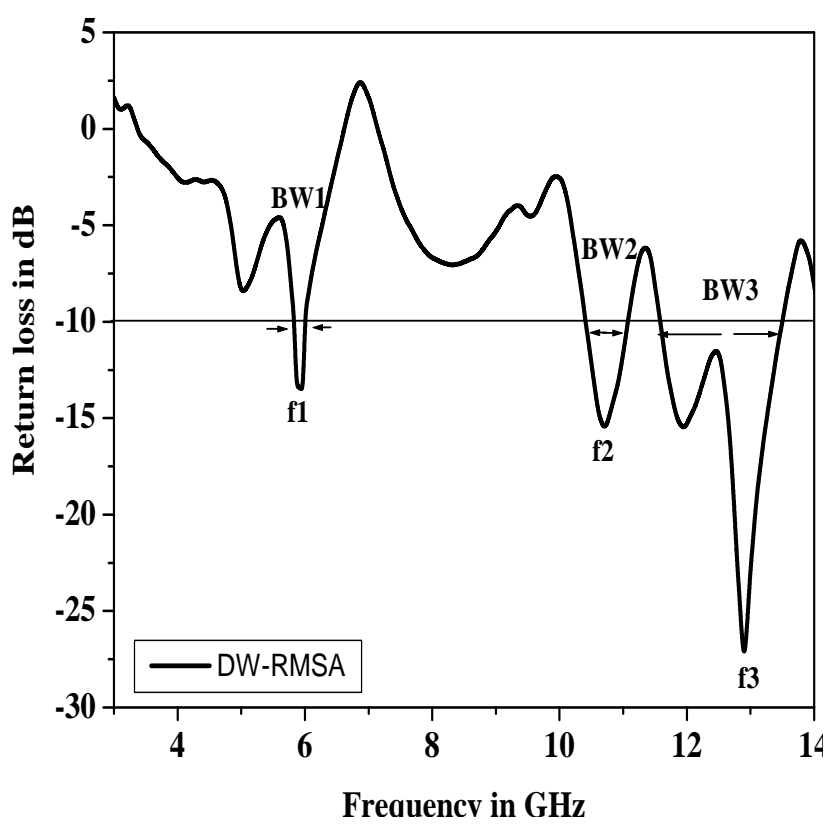

Fig- 8: The return loss characteristics versus frequency of DW-RMSAEBG

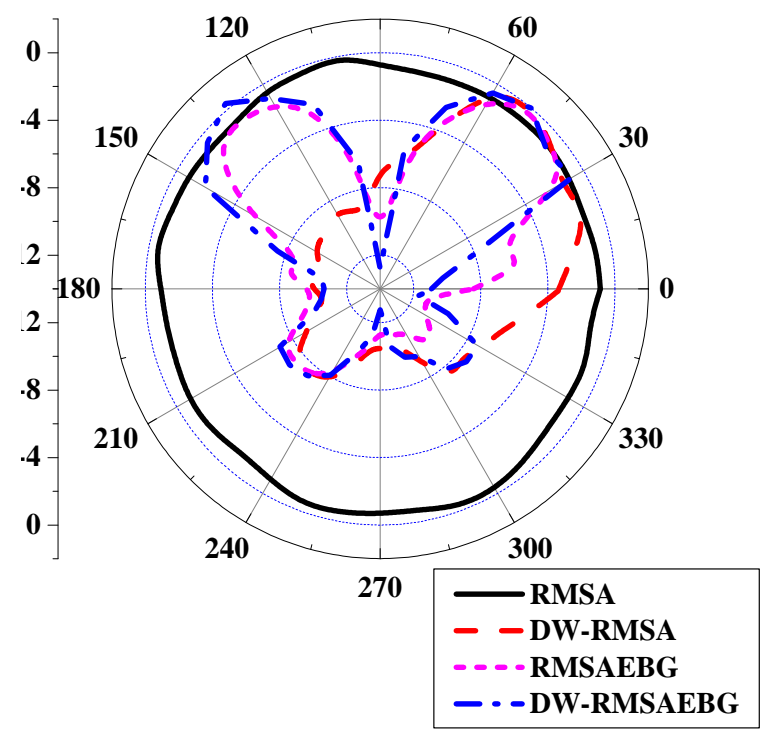

Fig.-9(a): E-plane Radiation pattern of RMSA, DW-RMSA, RMSAEBG, DW-RMSAEBG

Table-2: Results of proposed antenna

\begin{tabular}{|c|c|c|c|c|c|}
\hline Antenna & $\begin{array}{c}\text { Resonant } \\
\text { Freq. } \\
\text { ( GHz) }\end{array}$ & $\begin{array}{l}\text { Return loss } \\
\text { (dB) }\end{array}$ & $\begin{array}{l}\text { Bandwidth in } \\
\text { MHz }\end{array}$ & $\begin{array}{l}\text { Bandwidth } \\
\text { in (\%)age }\end{array}$ & $\begin{array}{c}\text { Overall } \\
\text { Bandwidth in }(\%) \text { age }\end{array}$ \\
\hline RMSA & 5.99 & -37.21 & 250 & 4.18 & 4.18 \\
\hline RMSA-EBG & $\begin{array}{c}4.14 \\
5.67 \\
7.07 \\
8.23 \\
9.05 \\
11.00 \\
\end{array}$ & $\begin{array}{l}-18.98 \\
-15.99 \\
-18.06 \\
-15.27 \\
-12.65 \\
-14.90 \\
\end{array}$ & $\begin{array}{c}22 \\
50 \\
75 \\
68 \\
126 \\
439 \\
\end{array}$ & $\begin{array}{c}5.31 \\
8.81 \\
10.60 \\
8.26 \\
13.92 \\
40.0 \\
\end{array}$ & 86.99 \\
\hline DW-RMSA & $\begin{array}{c}5.96 \\
10.71 \\
11.94\end{array}$ & $\begin{array}{l}-13.50 \\
-15.45 \\
-15.45\end{array}$ & $\begin{array}{c}22 \\
70 \\
192\end{array}$ & $\begin{array}{c}3.69 \\
6.53 \\
16.08\end{array}$ & 26.30 \\
\hline DWRMSA-EBG & $\begin{array}{c}4.07 \\
5.52 \\
7.97 \\
11.11 \\
11.92\end{array}$ & $\begin{array}{l}-15.88 \\
-25.33 \\
-14.46 \\
-12.76 \\
-18.65\end{array}$ & $\begin{array}{c}57 \\
229 \\
211 \\
46 \\
337\end{array}$ & $\begin{array}{c}14.0 \\
41.48 \\
26.47 \\
4.14 \\
28.27\end{array}$ & 114.36 \\
\hline
\end{tabular}




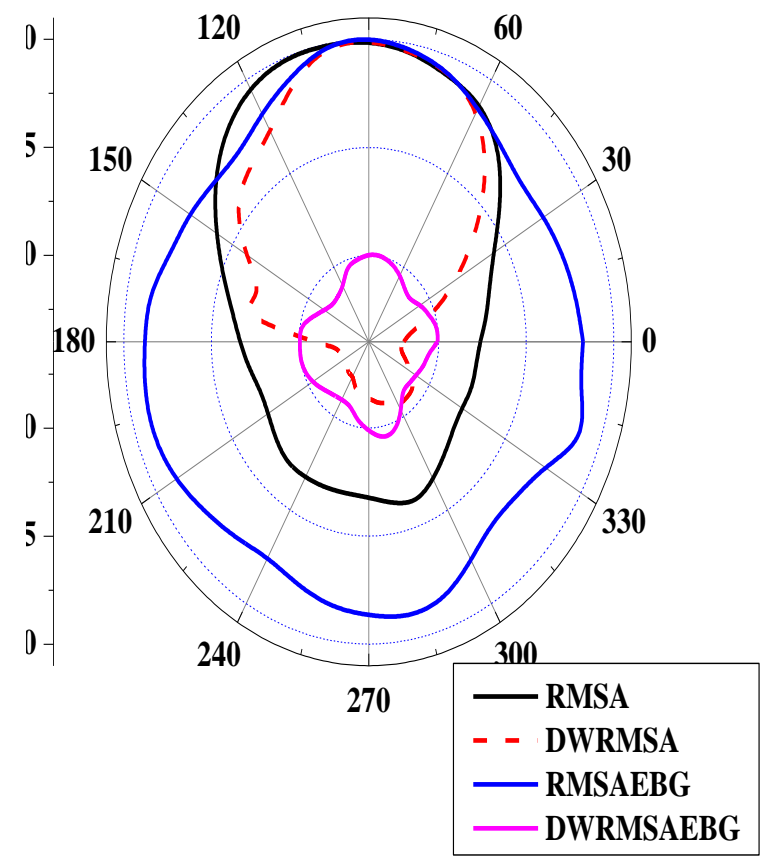

Fig.-9(b): H-plane Radiation pattern of RMSA, DW-RMSA, RMSAEBG, DW-RMSAEBG

\section{CONCLUSIONS}

A design technique for a high impedance EBG structure with microstrip antenna is described. In this design technique, the shape of the rectangular microstrip antenna is modified with dual slit and then the ground plane is replaced by the spiral EBG structure in order to enhance the bandwidth of the microstrip. In addition, the design technique is simple and easily realized with rectangular microstrip antenna fabrication, making it suitable to various wireless communications applications.

\section{ACKNOWLEDGEMENTS}

The authors acknowledge their thanks to, DST, New Delhi for sanctioning Vector Network Analyzer for measuring the parameters of fabricated antenna under FIST program.

\section{REFERENCES}

[1]. Balanis C.A. (1997) Antenna Theory, 2nd ed., New York: John Wiley \& Sons, Inc.

[2]. Dalia M.N. Elsheakh, Hala A. Elsadek and Esmat A. Abdallah Antenna Designs with Electromagnetic Band Gap Structures.

[3]. Mrs. Priti N.Bhagat, Prof. V. B. Baru" Rectangular Slotted Patch Antennas with EBG Structure" International Journal of System, Algorithms \& ApplicationsVolume 2, Issue ICRAET12, May 2012,pp 134-136.
[4]. Thakur O.P, Dwari S AND Kushwaha A.K" EnhancemenT of bandwidth by using photonic bandgap structure in microstrip antenna" International Journal of Computational Intelligence Techniques, Volume 3, Issue 2, 2012, pp 112-113.

[5]. Fan Yang And Yahya Rahmat-Samii "Electromagnetic Bandgap Structures In Antenna Engineering", Cambridge University Press, 2009.

[6]. Gaurav Kumar Sharma Narinder Sharma "Analysis of a Rectangular Microstrip Patch Antenna with EBG Structures" International Journal of Computer Applications (0975 - 8887) Volume 84 - No 13, December 2013 pp 39-42.

[7]. Shrikant Verma Monika Chauhan" Performance Enhancement of Butterfly Shape Microstrip Patch Antenna by Using Modified Ground Plane" International Journal of Engineering Technology \& Management Research Volume 1, Issue 1 February 2013, pp267-269

\section{BIOGRAPHIES}

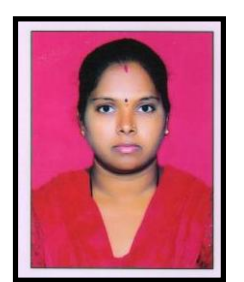

Savita M Shaka received her M Sc from the department of Applied Electronics from Gulbarga University, Gulbarga in the year 2006 and her M Phil from the same department in year 2008. Currently she is pursuing her Ph.D in the field of Microwave Antennas from the department of Applied Electronics, Gulbarga University, Gulbarga.

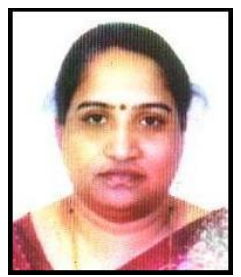

Vani R. M. received her B.E. in Electrical and Electronics from the B.I.ET., Davanagere and M.Tech in Industrial Electronics from S.J.C.E., Mysore, Karnataka. She has received her Ph.D in Applied Electronics from Gulbarga University, Gulbarga, India, in year 2005. She is working as Reader \& Head, University Science Instrumentation Center, Gulbarga University, Gulbarga, since 1995. She has more than 85 research publications in national and international reputed journals/Conference proceedings. she presented the research papers in National/ International conferences in India and abroad. She has conducted several courses, workshops for the benefits of faculties and field engineers. Her areas of interest are microwave antennas, PC based instrumentation, Embedded controllers and Wireless communication. She has one UGC major research project to her credit

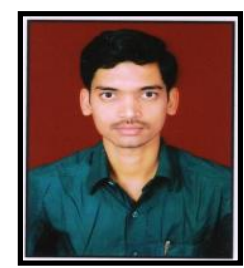

Prashant $\mathbf{R} \mathbf{T}$ received his $\mathrm{M}$ Sc fron the department of Applied Electronics Gulbarga University, Gulbarga in the year 2011. He worked as a Project Fellow in the UGC sponcerd Majore Reserch Project 20122013. Currently he is persuing his Ph. D in the field of Microwave Antennas from the 
department of Applied Electronics, Gulbarga University, Gulbarga.

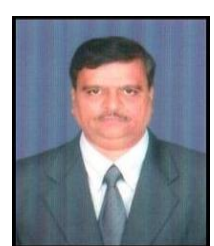

P. V. Hunagund, received his M.Sc and Ph.D from the Dept. of Applied electronics, Gulbarga University, Gulbarga, in the year 1982 and 1992 respectively. He is working as professor and chairman of Applied Electronics department, Gulbarga University, Gulbarga. He has more than 125 research publications in national and international reputed journals, more than 85 research publications in international symposium/Conferences. $\mathrm{He}$ presented the research papers in National/International conferences in India and abroad. He has guided many Ph.D and M.Phil students. He has three major research projects at his credit. 